\title{
JUVENTUDES E O MUNDO DO TRABALHO: CONFINAMENTO E A BUSCA POR PONTES POSSÍVEIS
}

\author{
Alexandre Bárbara Soares ${ }^{1}$
}

\begin{abstract}
Resumo
Este artigo procura discutir a questão da juventude e inserções no mundo do trabalho a partir da relação entre duas perspectivas: o isolamento e o confinamento. 0 território de análise é a cidade do Rio de Janeiro. Procuro discutir as diferentes visões dos jovens de baixa renda de um grande território urbano brasileiro acerca de suas possibilidades de inserção no mundo do trabalho, tendo como eixo central as mudanças e novas configurações deste universo, com ênfase nos aspectos do isolamento e confinamento. 0 artigo nasce de reflexões conceituais a partir de uma pesquisa composta por entrevistas e grupos focais junto a jovens de cinco das maiores comunidades de baixa renda da cidade.
\end{abstract}

Palavras-chave: Juventude. Trabalho. Isolamento. Políticas.

\section{ThE PROGRAMMATIC DISCOURSES OF POLITICAL PARTIES IN LATIN AMERICA: CLASS IDENTITY AND ECONOMIC POLICY}

\section{Abstract}

This article aims to discuss the issue of youth and insertions in the world of work from the relation between two perspectives: isolation and confinement. The research field is Rio de Janeiro city. I intend to discuss the different views of low income youngsters from a big urban Brazilian territory on their possibilities of

\footnotetext{
${ }^{1}$ Mestre em Psicologia Social e Doutorando do Programa de Pós-Graduação em Psicologia da Universidade Federal de Rio de Janeiro. aleprofissional@yahoo.com.br
} 
insertion in the world of work, considering the changes and new configurations of this universe, emphasizing the aspects of isolation and confinement. This article arises from the conceptual thinking of a research that comprised interviews and focus groups with young people from five of the largest low-income communities in the city.

Keywords: Youth. Work. Isolation. Policies.

\section{INTRODUÇÃO}

$\mathrm{E}$

m nível global, a juventude, em suas diferentes formas e representações, tem estado no foco dos debates, estudos e políticas nos últimos anos. Os discursos produzidos a partir da juventude, segundo diversos autores (BUTLER; PRINCESWAL, 2007; CASTRO, 2004; ABRAM0; BRANCO, 2005; PAIS, 2000), ainda se mantêm polarizados em duas perspectivas, em especial nos meios urbanos brasileiros. Uma delas é a da culpabilização sobre o aumento da criminalidade, especialmente em cidades como o Rio de Janeiro, focando a ótica sobre seus riscos e potenciais desvios. Na outra perspectiva, os jovens seguem sendo abordados e colocados como a "esperança para o futuro" do país, com óticas centradas em abordagens que privilegiam visões idealizadas sobre o "ser" jovem e suas distintas manifestações - o jovem "revolucionário", "corajoso", "empreendedor" e grande e único responsável por mudanças sociais profundas.

Ao mesmo tempo, a idéia de um mundo no qual os jovens se inserem na vida econômica dos países com uma intensidade crescente, representa um foco de discussões em larga escala. Mesmo em distintos contextos, a idéia de um tempoespaço comum à juventude dentro de um mundo cada vez mais homogeneizado permite que discursos e práticas transversais perpassem estas juventudes de maneiras similares.

Ao pensar nos diferentes discursos produzidos sobre a juventude e sua conexão com a participação dos jovens na vida econômica dos países, é comum escutarmos a expressão "cabeça vazia, oficina do diabo". Esta expressão, muito utilizada no cotidiano brasileiro, é recorrente para iniciar discussões e abordagens sobre a temática da juventude, em especial no que tange à juventude de baixa renda. 0 foco sobre a periculosidade dos jovens tem motivado muitos debates e um dos eixos centrais e mais recorrentemente abordado é o da relação entre "desocupação" e "criminalidade". Assistimos, na última década, a uma crescente 
criminalização da juventude na grande mídia e nos discursos em geral sobre esta parcela da população. Muitos são os estigmas associados aos jovens de baixa renda, em especial àqueles moradores de localidades conhecidas como favelas. Um deles é que todo jovem pobre, sem atividade laboral, é um potencial criminoso; ou de que nestas localidades de baixa renda, se não houver opções de trabalho, sejam quais forem, fatalmente os jovens irão se inserir em facções do tráfico de drogas. Tal linearidade constitui identidades marcadas pelo traço do preconceito e da discriminação a priori.

Entretanto, pouco se pergunta sobre a imensa massa de jovens que, a despeito de não estarem inseridos em atividades ilegais, estão alijados dos direitos básicos de desenvolvimento pleno, incluído aí o direito ao trabalho enquanto ferramenta de socialização, desenvolvimento social e cognitivo e enquanto dispositivo de ampliação de horizontes e oportunidades.

Partindo desta questão, propõe-se um primeiro exercício: olhar a questão destes jovens por outra ótica: a dos direitos, pensando nas fases do desenvolvimento deste cidadão e; no trabalho, como uma das etapas para este desenvolvimento e para sua inserção no contexto social. A visão de que no meio das diferentes frentes que constituem as identidades jovens - família, educação, lazer, cultura - 0 trabalho é mais uma, fundamental desde que articulada a todas as outras para a formação de sujeitos de direitos plenos. Assim, a visão sobre o trabalho e o jovem não parte de uma demanda paliativa - de que qualquer trabalho é bom desde que 0 jovem esteja ocupado - nem de uma perspectiva que leve em consideração o trabalho apenas como alternativa a uma possível "natureza desviante" deste jovem. 0 que está em cena é a perspectiva de que todos deveriam ter direito ao trabalho enquanto elemento constituinte de suas identidades e subjetividades, de quem são e com quem se relacionam. Esta visão simples é determinante na hora de analisar como os diferentes discursos sobre os jovens vão atuar na construção das distintas visibilidades sociais sobre estes, e na elaboração e formulação de propostas que incluam este jovem como ator ativo do processo de construção de relações mais equiitativas, tão necessárias ao contexto urbano atual.

Os jovens entre 15 e 24 anos representavam, em 2007, quase 17\% da população total da região metropolitana do Rio de Janeiro. A maior parte destes cerca de 12\% - estáentre os 18e 24 anos (IBGE, 2007). São cidadãos que trabalham, estudam, sustentam famílias, consomem, circulam, enfim, movimentam a economia e a vida social da cidade e do entorno. Ouvir estes jovens e identificar, 
em suas vidas, em seu cotidiano, quais as principais questões atravessam suas buscas por inserções no mundo do trabalho é fundamental na procura por pontes possíveis e alternativas viáveis.

As reflexões aqui presentes estão baseadas na Pesquisa "CIPROJOVEM Conhecimento e Práticas Inovadoras de Geração de Trabalho e Renda para Jovens em Comunidades de Baixa Renda", desenvolvida, entre os anos de 2006 e 2009, pelo Centro Internacional de Estudos e Pesquisas sobre a Infância (CIESPI), com 0 apoio da FINEP. 0 objetivo da pesquisa foi identificar, sistematizar e descrever estratégias que aproximassem jovens de baixa-renda da cidade a atividades de geração de trabalho e renda. A pesquisa foi realizada em cinco das maiores comunidades de baixa renda da cidade do Rio de Janeiro (Rocinha, Vila Aliança, Complexo do Alemão, Complexo do Caju e Distrito de Queimados-Fanchen) com jovens de 15 a 24 anos. Foram realizadas entrevistas individuais com jovens de diferentes características e seis grupos focais em cada localidade.

Entretanto, ao pensar a questão do trabalho e juventude de baixa renda na cidade, problematiza-se que, via de regra, este não é um problema unicamente da juventude moradora de favelas. No entanto, a necessidade de delimitar alguns escopos de análise levou à criação de estratégias e instrumentos para escolher locais que fossem representativos de uma amostra da cidade, sem reforçar estigmas e naturalizações do espaço urbano em relação às favelas. A primeira afirmação metodológica importante a se fazer é que pensar as questões da juventude de baixa renda, desenvolvimento econômico local e trabalho, hoje, nos grandes centros urbanos brasileiros, significa pensar na diversidade de "baixas rendas" que se apresentam neste espaço. Também é necessário ponderar que se as favelas representam um espaço de visibilidade da baixa renda, não se pode deixar de afirmar que os fenômenos ali estudados não são fenômenos exclusivos daquele espaço urbano. Concordando com Elias e Scotson (2000, p. 16), "os problemas em pequena escala de uma comunidade e os problemas em grande escala de um país são inseparáveis. Não faz muito sentido estudar fenômenos comunitários como se ocorressem em um vazio sociológico".

Por isso, quando se depara com a constante repetição de falas e silêncios contados sobre a relação "isolamento X confinamento", não se pode deixar de constatar que o que está em jogo é um repensar do modelo de cidade que queremos. E é sobre a relação trabalho-cidade-juventude que se pretende discorrer brevemente neste artigo. 


\section{COMUNIDADE, FAVELA, LOCALIDADE DE BAIXA RENDA: VIVENCIANDO DISTINTOS CENÁRIOS}

Para a população em geral e alguns formadores de opinião - grande mídia, alguns políticos e gestores, etc - as favelas e seus moradores podem parecer todos iguais, com as mesmas questões e desafios cotidianos: pobreza, tráfico de drogas, ausência de recursos, estrutura básica deficitária, desordem urbana e caos. Entretanto, nem todas as comunidades são iguais, nem todas as favela têm os mesmos problemas, nem todo morador e jovem, em especial, apresenta as mesmas vivencias e demandas. Pensar hoje no universo de juventudes de baixa renda da cidade significa pensar para além das representações comuns de morador de favelas para repensar um projeto de cidade que, pautado em similaridades, abarque as múltiplas diferenças entre as localidades, culturas e situações sócioeconômicas.

Em paralelo, penetrar no cotidiano de cinco comunidades de distintas regiões, com diferentes arranjos políticos, sócio-econômicos, históricos e demográficos permite identificar questões comuns que atravessam as distintas juventudes. Tais questões merecem destaque, podendo possibilitar passos em direção a programas que, respeitando as especificidades, possam garantir melhores condições de acesso ao mundo do trabalho para todos os jovens. Importante incluirmos no diagnóstico a imensa diferença de recursos - equipamentos sociais, redes e entornos, contextos econômicos - existente nas comunidades urbanas de baixa renda. Assim, inicia-se por esta básica, mas importante premissa: cada local é um local, cada comunidade tem sua vida, história e características e cada juventude de cada local apresentará diferentes demandas. Porém, onde se pode começar a identificar similaridades?

\section{O ISOLAMENTO E CONFINAMENTO: O DESAFIO DE VIVER NA “NÃO CIDADE"}

Em todos os grupos de jovens e entrevistas realizadas, um discurso constantemente ganhava corpo: o do isolamento destas localidades. Não apenas o isolamento físico de uma comunidade como Vila Aliança ou Grota (Complexo do Alemão), mas a sensação para estes jovens de que estão alijados da cidade enquanto espaço de construção de relações e laços. Acorrentados a certos espaços, físicos e simbólicos, destituídos de oportunidades e alternativas, terminam 
encurralados nas identidades atribuídas a este território. Os territórios, inspirandonos em Milton Santos, mais do que apenas espaços físicos onde os sujeitos nascem e crescem, emergem também como elemento constitutivo da identidade, propiciando aos indivíduos reconhecerem, de fora, quem são. Entretanto, na lógica do capital globalizado, os territórios adquirem valores distintos, construídos sem a participação dos indivíduos e que a estes se impõe. Assim, para estes jovens que moram em favelas que cotidianamente ganham visibilidade na grande mídia como espaços privilegiados de perigo e violência, o lugar de moradia é legitimado principalmente pela desvalorização e estigmatização, consolidando uma maneira de ver o território que se impõe a seus habitantes: "viver aí significa se ver e se produzir com a marca da marginalidade [lugar da margem, da beira, do fora], assim como da desqualificação" (CASTR0, 2004, p. 116).

Nos discursos dos jovens, um certo enraizamento com o local de moradia aparece em frases contraditórias que ora ratificam um sentimento de pertencimento forte e identidade com o espaço e relações, ora reproduz o discurso de segregação com a favela muito recorrente na cidade do Rio de Janeiro. Por exemplo, a idéia comum sobre a indolência dos jovens, reproduzida entre eles mesmos, é algo fortalecido tanto no cotidiano, pela grande presença de jovens que fora da escola e sem oportunidades de trabalho passam seus dias pelas ruas da comunidade, quanto pela legitimação de uma visibilidade social da juventude enquanto perigosa e potencialmente desviante.

Um dos sinais é sempre remetido à questão do preconceito por morarem em favelas ou comunidades de baixa renda. Os jovens das comunidades, de maneira geral, relatam receio de preencher fichas de trabalho com seus endereços verdadeiros. Em todos os momentos da pesquisa, este fator aparece como primário em relação aos obstáculos para conseguirem uma inserção. Os jovens sabem que vivem em um território marcado dentro do espaço urbano e desenvolvem estratégias para tentar superar esta marca. Muitos jovens do Complexo do Alemão relatam que, na hora de dar seus endereços, falam que moram em "Inhaúma" (um dos bairros próximos ao Complexo). Alguns jovens em grupos focais relataram que já perderam oportunidades e foram colocados sob desconfiança por morarem no Complexo.

Ou seja, é importante garantir que os jovens possam exercer seus direitos básicos ao poderem "superar o espaço" e não serem constrangidos por viverem nele (CASTRO, 2004, p. 43). Assim, se a luta por um espaço de inserção já é um 
desafio por si só, o fato de viver em dada localidade não deveria ser um obstáculo a mais que garanta a não equidade do processo.

Esta percepção é mais explícita - porém não exclusiva - entre os jovens moradores de regiões menos centrais e turísticas da cidade, como Vila Aliança, Queimados e Complexo do Alemão. Especialmente em Queimados e Vila Aliança, o conflito de viverem em uma região metropolitana com características rurais, em alguns momentos, parece ser um fator de forte apreensão e desconforto, visto que as oportunidades e 0 acesso se tornam mais distantes, apesar da proximidade com grandes centros geradores de oportunidades - graças à rede precária e deficitária de transportes públicos e da pouca informação sobre oportunidades nas regiões mais centrais.

Este fato cria alguns comportamentos e atitudes que podem ser vistas, à primeira vista, como despreparo para o mundo do trabalho, mas que logo se revelam maneiras de operar desta localidade que se naturalizaram. Um exemplo foi o dos jovens que participaram de um dos grupos focais para homens em uma das comunidades de Queimados. Alguns disseram que foram ao grupo com a expectativa de que conseguiriam algum trabalho. Um deles estava sem camisa, de boné e sandálias. Ao ser perguntado que tipo de trabalho esperava encontrar respondeu: "qualquer um". 0 fato de vivenciar um distanciamento físico e concreto das oportunidades de trabalho e formação parece fazer com que a informalidade em todos os momentos seja a tônica da relação com e entre estes jovens. Assim, para um jovem que teve poucas oportunidades e que divide com seus pares esta mesma realidade, a forma de apresentação e as expectativas são diretamente relacionadas à ausência de possibilidades concretas de alcançar alguma entrada no mundo do trabalho. 0 preconceito, do qual se dizem vítimas, parece ser retroalimentado por esta ausência de aproximações, pontes entre o mundo formalizado do trabalho e a realidade cotidiana. 0 confinamento é alimentado por toda uma ordem de dificuldades de circulação pela cidade, por parte dos moradores das localidades de baixa renda, enquanto expressão física e simbólica da limitação de oportunidades propiciada pela circulação, pelo encontro com o diverso.

Finalmente, é necessário abordar a questão da mobilidade interna, que se torna complexa e sempre muito instável - gerando o fenômeno do confinamento, ou seja, da reclusão em espaços fechados e da inacessibilidade do espaço da rua. Operações de enfrentamento da polícia contra o tráfico de drogas, ocorrendo durante os primeiros momentos da manhã e em horários de ida de crianças e 
adolescentes para escola, têm sido constantes em comunidades como Vila Aliança e Complexo do Alemão, nos últimos cinco anos, Estes enfrentamentos criaram toda sorte de problemas: do medo e receio das famílias de levarem seus filhos para a escola, ao êxodo de professores destas mesmas escolas, que ficam em áreas mais expostas; da impossibilidade dos jovens de ir ou voltar pra casa do trabalho, até o fechamento de uma das escolas, como em Vila Aliança, e o cancelamento de linhas de ônibus em determinadas regiões após determinado horário. Este constante estado de medo não pode ser vilipendiado quando se analisam obstáculos para uma boa inserção e para a relação "favela X cidade", pois instaura o terror nas relações mais básicas e cotidianas.

Pesquisa recente do PÓLIS/IBASE (2008), realizada em sete diferentes países sul americanos, diagnosticou esta necessidade expressa dos jovens pelo direito à circulação pelas cidades. Nos diferentes contextos pesquisados, os jovens expressam a importância desta circulação na experimentação e ampliação de redes sociais e de referência. Da mesma maneira que os jovens ouvidos em nossa pesquisa, por mais que demandem um melhor aparelhamento de suas comunidades (oportunidades de formação, serviços, lazer e cultura), desejam usufruir os espaços e oportunidades oferecidos em outras regiões da cidade. Como dito anteriormente, desejam o "direito à cidade" (PÓLIS/IBASE, 2008, p. 42).

0 que fica explícito neste tópico - e demanda um enfrentamento imediato - é que existe hoje, em grande parte dos grandes centros urbanos brasileiros, uma forma invisibilizada de imobilidade e confinamento social que inibe a uns e garante a outros o acesso a outros espaços urbanos da cidade. Este movimento trabalha diretamente no sentido de uma fragmentação entre os distintos setores sociais, alimentando e acentuando preconceitos e antagonismos e condicionando o desenvolvimento de muitos e muitos jovens apenas ao limitado espaço urbano a que têm acesso. A construção de um projeto de cidade que envolva e permita a todos a plena circulação - por meio de uma rede de transporte público extensa e também acessível, através de benefícios como passes livres, descontos progressivos e acessibilidade plena, assim como a garantia de incorporação destas populações na agenda pública de cultura, educação e geração de oportunidades eqüitativas e não "exclusivas" - é ponto crucial na geração de novas conexões que são a mola mestra da busca por novas oportunidades de entrada no mundo do trabalho. Afinal, hoje, "a desigualdade se encontra cada vez mais vinculada ao isolamento" (SENNET, 2006, p. 55). 


\section{A FORMAÇÃO COMPLEMENTAR: A CULTURA DOS CURSOS E O CONFINAMENTO DO CONHECIMENTO}

Em comunidades como a Rocinha ou o Complexo do Alemão foi comum ouvir sobre a existência de uma "cultura de cursos" que, ao mesmo tempo em que cumpre uma função de preencher o currículo do candidato, mostra-se, segundo os jovens, ineficaz na instrumentalização de condições concretas para geração de oportunidades no mundo do trabalho. Em localidades mais distantes como Queimados, a demanda por cursos extracurriculares é grande e mesmo aqueles que parecem existir em maior número em outras localidades - como informática básica, por exemplo - existem em menor escala ali. Um dos jovens, quando questionado sobre o que poderia incrementar as chances de concorrer no mundo do trabalho, afirma que:

Um curso de informática, alguma coisa... soldador pra negócio da Petrobrás que eles tão pedindo curso pra quem solda, é... construção civil... tudo, precisando de curso pra poder a gente ter bastante currículo pra poder encaminhar (Jovem homem, Queimados - 18 anos, grifo nosso).

0 vazio dos discursos e oportunidades se reflete em um vazio curricular que pede um preenchimento, no sentido operacional, de criar outras credenciais de concorrência no mundo do trabalho. Em geral, os cursos surgem no discurso dos jovens menos como um conjunto de ferramentas e mais como um conjunto de credenciais, títulos, carimbos que possibilitem ao possível empregador oferecer uma oportunidade a ele. A ausência de tais elementos de preenchimento, de vazios em seus currículos, os aprisiona aos espaços estigmatizados dos que não tem "competências" para se apresentar frente ao mundo do trabalho.

Assim, o paradigma da capacitação ainda aparece normatizado pelo paradigma da acumulação de algum conhecimento, em contraposição à perspectiva crescente de se capacitar para o trabalho através de processos (SENNET, 2006). Segundo este autor, a ênfase dos processos formativos hoje está mais pautada na capacidade de "saber apreender" algo, do que em "saber algo". Tal capacidade para o trabalho e aprendizado por processos, de pensar de maneira prospectiva sobre "o que deveria ser feito" termina por "penalizar o esforço de aprofundamento" (SENNET, 2006, p. 113) de questões, de conteúdos, de saberes. Ao mesmo tempo, os jovens reconhecem que a necessidade de se capacitar está relacionada a todo um conjunto de habilidades necessárias que nem são garantidas pelo sistema formal de educação, nem estão disponíveis em 
seus cotidianos de relação - como, por exemplo, os cursos de inglês ou as noções de relacionamento interpessoal em voga em algumas iniciativas de capacitação hoje. Entretanto, para além da necessidade de aumentar o numero de credenciais ou incrementar a quantidade de ferramentas, há uma constatação cada vez mais concreta no mundo do trabalho sobre o tempo de duração de uma capacitação cada vez menor. 0 que se sabe hoje não garante a permanência em um posto ou local de trabalho, visto que tal conhecimento apresenta um tempo de pregnância associada ao trabalho realizado cada vez menor.

Com o crescimento do aparato de tecnologias - de toda ordem, inclusive as sociais - as capacitações têm prazo para vencer e demandam constante atualização, colocando-nos constantemente no lugar de "falta" e operando em uma reorientação de seu sentido: a capacitação, seja qual for, não é mais um "bem durável" (SENNET, 2006, p. 85). Agora, o que está em alta enquanto valor passa a ser a "capacidade de fazer algo novo", a capacidade de abrir mão de uma capacidade estabelecida e adaptar-se a novos cenários. Em contrapartida, aqueles que não se mostrem aptos a se adequar a tais novas condições - de rápido aprendizado e mobilidade constantes - se tornam fortes candidatos a ocupar o que Castel (1998) chama de "suprenumerários", ou aqueles que se encontram alijados do circuito de signos sociais - trabalho - consumo - economia.

Novas habilidades são necessárias ao desempenho de novas tarefas no mundo moderno, e estas não são necessariamente apreendidas apenas com informação, mas com processos. Um exemplo que não é vivido apenas por jovens de classes baixas, mas pelos extratos médios, é relacionado ao setor de serviços em nossa cidade. Em uma seleção de trabalho para atendente de lojas em um shopping center - uma ocupação não especializada -, uma jovem que tenha viagens para o exterior e uma vivência maior com outras pessoas e culturas pode ter maiores chances que outra que, a despeito de cursos de formação em técnica de vendas, não tenha tido a mesma vivência. Trata-se do processo de "poder vir a ser pela experiência", em detrimento do "conhecimento que se acumulou".

Entretanto, como coadunar esta demanda dos dias modernos - que está latente na área de serviços, de tecnologiae de informação, importantes naeconomia carioca, por exemplo - com a reprodução da cultura acumulativa da educação tradicional? A chave parece ser a conciliação entre novos conhecimentos técnicos e a possibilidade, expressa pelos jovens, de uma ampliação das possibilidades de relação destes com áreas e atmosferas mais amplas do espaço urbano. 0 reforço 
do aprendizado vivencial - através da oportunização de acesso a outros espaços de cultura, lazer, entretenimento e mesmo tecnologia, em grande parte, hoje, intuitivas - em contraponto à constante demanda por capacitação, que promove cada vez mais a sensação de incapacidade nas pessoas, é o que Sennet (2006, p. 86) denomina de "o fantasma da inutilidade".

\section{ENTRE A “INDICAÇÃO" E O “CONHECIMENTO": O PAPEL DAS REDES DE RELACIONAMENTOS NA BUSCA POR SAÍDAS POSSÍVEIS}

Quando perguntados sobre o que pode ajudar - ou efetivamente ajuda - a ter maiores oportunidades de entrada no mundo do trabalho os jovens hegemonicamente falavam a mesma frase: ter "indicação", "ter conhecimento". Esta expressão, quando aprofundada nas conversas podia ter múltiplas significações: desde um conhecido que ao saber que em algum lugar estavam à procura de alguém para preencher determinada vaga, informou ao amigo, passando pelo parente e/ou amigo, que informou que onde ele trabalha haveria ou existia uma vaga a ser preenchida; até o caso de pessoas (amigos e/ou parentes) que ao saberem de vagas disponíveis, em seus lugares de trabalho, indicavam ao chefe/responsável um amigo e/ou parente para assumir a vaga. Em todas as experiências, distintos cenários se apresentam que podem ser explorados.

Em um primeiro cenário, o que está em questão é o circuito de informação que permite ao jovem saber "onde estão as oportunidades". Quando perguntados sobre "como fazem para procurar trabalho", pouquíssimos jovens afirmaram utilizar as formas tradicionais: anúncios (em jornais ou internet) e agencias públicas de trabalho (como os CAT's - Central de Apoio ao Trabalhador - do Governo do Estado/RJ). Em contraponto, quase todos afirmaram que avisam aos amigos e parentes que estão à procura de trabalho ou, simplesmente, saem procurando avisos expostos pelas ruas do bairro ou do centro do Rio, ou nos casos de jovens da Rocinha, por exemplo, levam currículos nos shoppings da zona Sul. Ao afirmarem, neste cenário, que a indicação é o fundamental, os jovens colocam em questão que o sistema de circulação de informações é complexo e não costuma chegar a estes de maneira tão convencional. Este não é um fenômeno exclusivo nem dos jovens nem das camadas populares, tendo em vista, por exemplo, a lógica de contratação de organizações privadas, por exemplo, que circulam e-mails e chamadas de oportunidades apenas em suas mailing-lists. 
0 segundo cenário que se vislumbra é próximo ao primeiro, mas envolve proximidade e confiança. Ou seja, depende do grau de conhecimento que 0 individuo tem tanto da pessoa, quanto das habilidades necessárias a serem desenvolvidas na ocupação. Uma pessoa que indica ao outro que onde trabalha existe uma vaga, conhece o que deve ser feito e pode, em grande parte dos casos, "direcionar" mais o aviso aos pares que acredita tenham mais possibilidades de consegui-la. Alem disso, alimenta a circulação de informações pela esperança da reciprocidade, fortalecendo sua rede pessoal.

0 terceiro cenário está mais conectado àquilo que, em linhas gerais, sedimentou-se enquanto uma das maiores ambigüidades da cultura brasileira: o famoso Q.I. ("quem indica"). Ao mesmo tempo em que publicamente é satanizado como a formalização da iniqüidade de oportunidades - visto que 0 mérito é suplantado pelo elo pessoal - é o mais confiável e desejado caminho para a obtenção de oportunidades menos concorridas e mais adaptadas às habilidades do individuo - visto que ninguém indicaria uma pessoa que não acreditasse poder desenvolver aquela ocupação, sob o risco de "se queimar" perante os superiores. Entretanto, este cenário foi o que menos apareceu nas entrevistas, sendo os dois primeiros os mais presentes no item "indicação".

Desta maneira, o que de fato está em questão? Um primeiro passo é a tensão impessoalidade X competência, ou seja, o desejo da impessoalidade no embate com a cultura da proximidade e personalização. Da Matta (1979) já produziu uma bem aprofundada análise da cultura brasileira e do embate entre a distinção entre individuo e pessoa, entre aqueles que são ímpares no contexto social e aqueles que se perdem no meio da multidão. Aqui, o que está em questão parece ser menos a possibilidade do individuo se distinguir perante as oportunidades, buscando a impessoalidade das seleções técnicas enquanto dispositivo de equidade, mas, principalmente, as limitações dos sistemas de circulação de informações associados à restrição das circulações de toda ordem - retornando, pois, à questão do confinamento dos jovens. Ao mesmo tempo, provoca-os a se colocarem em relação à pequena crença na competência enquanto condicionante único e primordial para a inserção no mundo do trabalho e do mérito - que pode estar incluso até mesmo nas relações pessoais ("fulano trabalha muito, ele merece esta chance") - enquanto atenuante das desigualdades vividas.

Também se fala de um ethos muito particular que merece atenção: a personalização e proximidade, vivenciada nas comunidades de baixa renda, 
seja pela necessidade, pela disposição física ou pelos elos de território (nunca "naturais"), em contraponto à cultura da impessoalidade. Esta cultura, ao mesmo tempo em que é desejada nos discurso - pois idealmente proporcionaria que a competência fosse mais imparcialmente avaliada - é negada na vivencia cotidiana, na que o que demarca os elos é o grau de personalização das relações. Alvito (2001), ao desenvolver uma pesquisa antropológica na favela de Acari, na zona Norte do Rio, relata que a primeira vez em que se sentiu parte daquele espaço, em relação aos sistemas de relação pessoais, foi quando pela primeira vez foi chamado por um apelido jocoso, em contraponto à alcunha de "professor", com a qual todos se referiam a ele. Esta forma de operar das camadas populares já foi extensamente estudada, mas é importante dizer que apenas se reproduz nos modos de assegurar maiores oportunidades de entradas. Ou seja, proporcionando alternativas ao confinamento.

Entretanto, é importante atentar que os jovens falam também de dois aspectos fundamentais: a necessidade de redes sociais mais amplas que expandam os territórios físicos e simbólicos para outras direções, permitindo que as oportunidades também se expandam a outros sentidos; e a reestruturação dos sistemas formais de informação que encontram diversos obstáculos quando colocados à frente das realidades destas localidades. Ou seja, a impessoalidade que marca websites, anúncios em jornais, cartazes pela cidade não oportuniza aos jovens que vivenciam outras redes de relações à condição de acolhida a estes chamados. Assim, o que está "na cara" nem sempre é "acessível".

\section{“Postura”, “EducaÇÃo” E “Cidadania”: O QUE É PRODUZIDO PELO CONFINAMENTO?}

Ao mesmo tempo e em paralelo à recorrente construção de periculosidade sobre a população jovem, muito disseminada pela imprensa e autoridades em geral, existe entre os jovens das comunidades um discurso recorrente sobre a necessidade de mais "postura" e "educação" destes em relação à presença de seus pares no mundo do trabalho.

A discriminação sofrida e o confinamento em lugares pré-estabelecidos parecem aqui já ter ocupado seu lugar em termos de auto-imagem identitária. Além disso, os próprios jovens relatam sobre os amigos que, segundo eles, "não fazem nada" ou "são vagabundos". Esta idéia fala diretamente da legitimação 
de uma visibilidade social da juventude enquanto perigosa e potencialmente desviante que, quando reproduzida pelo próprio jovem, pode garantir ao emissor da fala um lugar neutro em relação a tal visibilidade. Em compasso com este discurso encontramos, através de entrevistas com jovens em projetos e programas de formação, muitas falas sobre a necessidade de garantir a estes jovens acessos a uma maior "cidadania" que estaria expressa em uma tríade "informaçãocapacitação-inserção". Entretanto, o foco da ação ainda é o "cidadão" e não 0 conjunto de fatores conjugados que cotidianamente nega ou obstaculariza a este jovem acesso a maiores oportunidades de desfrutar de sua plena cidadania. Ou seja, viver nas condições que muitos dos jovens entrevistados vivem, enfrentando toda a horda de dificuldades e vivenciando a precariedade de serviços e oportunidades, é, por si só, uma usurpação de alguns de seus princípios básicos de cidadania, que dependeriam menos de um processo de "reeducação" do jovem e mais de um enfrentamento público e político destas desigualdades na esfera dos espaços de defesa de direitos. Quando a responsabilidade pelo acesso à cidadania fica expressa apenas em uma ponta do processo - 0 indivíduo - a equidade desta relação já se encontra comprometida.

Ao mesmo tempo, é possível analisarmos um paradigma crescente e muito disseminado no imaginário jovem e na sociedade de consumo em geral: o que você é e o que você faz. Os jovens entrevistados vivem atravessados pelas mesmas produções de subjetividade hegemônicas, que produzem a ambigüidade de ter que desenvolver habilidades que falem dos processos vividos e de um "poder vir a ser", em contraponto à demanda de "vender" personalidades e características que sejam suficientemente fortes ou pregnantes para convencer os empregadores sobre suas potencialidades.

Em geral, a identidade não diz respeito apenas ao que fazemos, mas também ao lugar a que nos integramos. Vários autores já chamaram a atenção sobre a importância que os indivíduos conferem à capacidade de serem incluídos em categorias específicas. Algumas situações de trabalho formalizado parecem exercer ainda sobre a juventude - a despeito de todo o discurso moderno sobre o "empreendedorismo jovem" - um fascínio por falarem de identidades mais conectadas a posições de prestígio, que seriam mais formalizadas e, portanto, demandariam "outra forma de operar", outra "educação", outro "ethos" distinto do que se convencionou chamar do comportamento do "favelado". A reboque desta perspectiva, vêem as formações ligadas a noções de "cidadania", comportamento 
e todas as outras referências a uma juventude que, aparentemente, por estar conectada a uma "outra" identidade, estaria desprovida.

Assim, entre voltar sua visão para seu próprio espaço com um olhar atravessado por pré-concepções hegemonicamente produzidas e garantir outras formas de expressão que, mantendo suas características, obedeçam a uma lógica mais formalizada, os jovens seguem carregando o peso de serem os únicos e totais responsabilizados pelas condições que enfrentam, tendo que resgatar uma cidadania e comportamentos perdidos, em meio ao turbilhão de obstáculos que dia a dia se colocam em nome de uma cidadania negada.

\section{Algumas Questões finais}

Entender as diferentes dimensões da questão da juventude e sua inserção no mundo do trabalho hoje, na cidade do Rio de Janeiro e nos grandes centros urbanos, significa ir mais fundo em relação às visões hegemonicamente constituídas sobre esta população. Significa, para começar, reconhecer que 0 campo da juventude e geração de trabalho e renda envolve variáveis tão diversas quanto complementares.

Destaforma, uma questão importanteéque o tema tem sido recorrentemente tratado como uma problemática do campo do trabalho e renda apenas, quando na verdade esta é a faceta mais explícita de um ciclo de exclusão e confinamento ao qual estão sendo submetidos os jovens de baixa renda cariocas e de outros centros urbanos. Romper com o isolamento e o silêncio, reconhecendo estes jovens como sujeitos de direitos e não apenas como "ameaças" à ordem urbana, que precisam de quaisquer tipos de medidas amortizadoras para "tranquilizá-los”, pode ser um primeiro passo no sentido de políticas mais concretas de aproximação destes e da cidade enquanto espaço de construção de relações.

Outro passo é o reconhecimento da necessidade de começarmos a desenhar novos projetos de cidade, que envolvam estas áreas consideradas "de risco" ou empobrecidas, garantido a seus moradores serviços e aparelhos públicos hoje de difícil acessibilidade. Isto é, investir em um projeto de cidade que privilegie outras formas de apropriação do espaço urbano mais agregadoras e que acolham as distintas manifestações juvenis. Para isso, entre outros passos, é importante priorizar a rede de transporte público, promovendo a plena acessibilidade e circulação dos espaços da cidade, inclusive daqueles de cultura e lazer, permitindo 
aos jovens que permaneceram por tempos confinados apenas a seus territórios de sobrevivência 0 acesso a outras partes da cidade ainda desconhecidas ou pouco exploradas.

Por fim, é necessário problematizar o caráter de irreversibilidade das mudanças do mundo do trabalho atualmente, que afetam aos jovens, mas, também aos adultos, que encontram cada vez mais dificuldades de lidar não apenas com a inserção, mas como o desafio de enfrentar o "fantasma da inutilidade" (SENNET, 2006). A lógica moderna do trabalho é forjada não mais na capacidade de apreender e empregar tal conhecimento, mas de ser capaz de mudar e rearranjar suas capacidades. Diante disso, não mais está em jogo o que se sabe e se construiu apenas, mas um "poder vir a ser" que demanda despreendimento e flexibilidade para as quais não fomos preparados, seja na escola, seja no imaginário sobre trabalho. Os pais dos jovens enfrentam a roda de sobreviver a subempregos, enquanto seus filhos e agregados tentam superar este ciclo atravessados por produções de "sucesso/fracasso" maciçamente produzidas no cotidiano, eliminando o tempo do erro e do aprendizado e agindo sobre seus corpos como elementos de imobilismo, perante 0 mundo que se fecha a seus esforços e demandas. Os novos trabalhos demandam dos jovens um aprofundamento de suas habilidades através da prática, mas não toleram o tempo dos processos, reprimindo suas possibilidades de entender outras lógicas de funcionamento e mantendo-os na reprodução de conhecimentos e práticas constituídas, limitando suas possibilidades de crescimento e rompimento do ciclo de pobreza. Mantendoos confinados em seus territórios físicos e simbólicos de demanda e falta.

Alijadosdo "statusdeelite" (BORDIEU, 1999, p. 58), as massastrabalhadoras e populares se vêem diante do duplo desafio de acumular conhecimento em circunstâncias adversas e apreender a lidar com a flexibilidade e o movimento que caracterizam as relações e processos de trabalho modernos - em especial nas áreas de serviços e ocupações manuais de rotina, como no Rio de Janeiro. 0 status que Bordieu apresenta pode ser simplesmente relacionado à legitimidade, à autoridade de ato, que a alguns é negada e a outros possibilitada. Quando se fala do acesso das distintas juventudes cariocas a novas possibilidades de geração de trabalho e renda, fala-se da constituição de outros status de legitimidade a estas populações que permitam que, mantendo suas especificidades, constituam um ethos próprio para aliançar-se à cidade "legalmente constituída", legitimada, que segrega e afasta os corpos que parecem não competentes ao desempenho das funções exigidas. 
Agregar e conectar é preciso. Mais do que apreender, capacitar ou "dar voz" e "cidadania" aos jovens; construir pontes e aproximar distintas perspectivas pode ser a chave para a superação de um conjunto de problemáticas que afetam nossas distintas juventudes, desperdiçando, ano após ano, milhões de potenciais vidas que terminam suas trajetórias pelas ruas e portas de casa das comunidades do Rio de Janeiro.

\section{REFERENCIAS}

ABRAMO, Helena; BRANCO, Pedro Paulo (Org.). Retratos da juventude brasileira. São Paulo: Abramo, 2005.

ALVITO, Marcos. As cores de Acari. Rio de Janeiro: Fundação Getulio Vargas, 2001. BOURDIEU, Pierre. A escola conservadora: as desigualdades frente à escola e à cultura. In: Escritos de educação. 2. ed. Petrópolis: Vozes, 1999. p. 39-64. BUTLER, Udi; PRINCESWAL, Marcelo. Culturas de participação: jovens e suas percepções e práticas de cidadania. Rio de Janeiro: CIESPI, 2007. (Relatório de Pesquisa).

CASTEL, Robert. As metamorfoses da questão social: uma crônica do salário. Rio de Janeiro: Vozes. 1998.

CASTR0, Lucia Rabelo. A aventura urbana: crianças e jovens no Rio de Janeiro. Rio de Janeiro: 7 Letras, 2004.

DA MATTA, Roberto. Carnavais, malandros e heróis. São Paulo: Rocco, 1979.

ELIAS, Norbert; SCOTSON, John L. Os estabelecidos e os outsiders: sociologia das relações de poder a partir de uma pequena comunidade. Rio de Janeiro: Jorge Zahar, 2000.

INSTITUTO BRASILEIRO DE GEOGRAFIA E ESTATÍSTICA (IBGE). Pesquisa Nacional por Amostra de Domicílio. Brasilia. 2007.

INSTITUTO DE ESTUDOS, FORMAÇÃO E ASSESSORIA EM POLÍTICAS SOCIAIS (PÓLIS); INSTITUTO BRASILEIRO DE ANÁLISES SOCIAIS E ECONÔMICAS (IBASE). Juventude e integração sul-americana: caracterização de situaçõestipo e organizações juvenis. Rio de Janeiro, 2008. (6 demandas para a construção de uma agenda comum).

PAIS, José Machado. Transitions and youth cultures: forms and performances. International Social Science Journal, v. 52, n. 164, 2000.

SENNET, Richard. A cultura do novo capitalismo. Rio de Janeiro: Record, 2006. 